\title{
High-Risk Polymorphisms Associated with the Molecular Function of Human HMGCR Gene Infer the Impedance of Cholesterol Biosynthesis
}

\author{
Keshob Chandra Das ( $\nabla$ keshob@gmail.com ) \\ National Institute of Biotechnology \\ Mohammad Uzzal Hossain \\ National Institute of Biotechnology \\ Md Moniruzzaman \\ National Institute of Biotechnology \\ Md Salimullah \\ National Institute of Biotechnology \\ Sharif Akhteruzzaman \\ University of Dhaka
}

Research Article

Keywords: HMGCR, hypercholesterolemia, functional and structural assessments, therapeutics

Posted Date: August 17th, 2021

DOI: https://doi.org/10.21203/rs.3.rs-753324/v1

License: (c) (i) This work is licensed under a Creative Commons Attribution 4.0 International License. Read Full License 


\section{Abstract}

Background: HMG-CoA reductase or HMGCR (3-Hydroxy-3-methylglutaryl-CoA reductase) is a rate-limiting enzyme involved in cholesterol biosynthesis. HMGCR plays an important role in the possible occurrence of hypercholesterolemia leading to atherosclerosis and coronary heart disease. This enzyme is a major target for cholesterol lowering drugs such as "statins" which blocks the synthesis of mevalonate, a precursor for cholesterol biosynthesis. This study aims to characterize deleterious mutations and classify functional Single Nucleotide Polymorphisms (SNPs) of the HMGCR gene through analysis of functional and structural evaluation, domain association, solvent accessibility, and energy minimization studies.

Results: Among 6,815 SNP entries from different databases, approximately 388 SNPs were found to be missense. Analysis showed that seven missense SNPs are more likely to have deleterious effects. A tertiary model of the mutant protein was constructed to determine the functional and structural effects of the HMGCR mutation. In addition, the location of the mutations suggests that they may have deleterious effects because most of the mutations are resides in the functional domain of the protein. The findings from the bunch of bioinformatics tools predicted that rs147043821 and rs193026499 missense SNPs could cause significant structural and functional instability in the mutated proteins of the HMGCR gene.

Conclusion: Therefore, the results of the current study would undoubtedly be accommodating in future endeavors concerning drug discovery and therapeutics against hypercholesterolemia.

\section{Background}

Hypercholesterolemia, or elevated blood cholesterol levels, is a condition associated with an increased risk of atherosclerosis and coronary heart disease [1]. These cardiovascular diseases are the result of elevated serum Low-density lipoprotein (non-HDLC) cholesterol levels. The variations in non-HDL cholesterol among individuals are a result of disparities among the genes involved in the biosynthesis of cholesterol as well as environmental factors such as diet and lifestyle [2-4].

Cholesterol is one of three major classes of lipids; the complex procedure of cholesterol biosynthesis is essential for all animal life. The process of Cholesterol biosynthesis begins with the Mevalonate pathway and the rate-controlling enzyme of this pathway is called 3-hydroxy-3-methylglutaryl-coenzyme A reductase (HMG-CoA reductase or HMGCR) [5, 6].

HMGCR is regulated via a negative feedback mechanism mediated by sterols and non-sterol metabolites derived from mevalonate. Usually, in mammalian cells, this enzyme is repressed by cholesterol derived from the internalization and degeneration of low-density lipoprotein (LDL) via the LDL receptor. The expression of LDL receptors in the liver is induced by competitive inhibitors of the reductase, which in turn upsurges the catabolism of plasma LDL and lessens the plasma concentration of cholesterol, an important factor of atherosclerosis [7-11]. Thus, HMGCR serves as a target for the cholesterol-lowering drug, statin. Statins are a class of drugs that act as competitive inhibitors of the enzyme. The inhibition of the enzyme by the drug reduces the rate by which HMGCR can produce mevalonate, the next molecule in the cascade that eventually produces cholesterol. This is significant because most circulating cholesterol comes from internal manufacture rather than a diet. When the liver can no longer produce cholesterol, the liver cells begin to express LDL-receptors on their surface, which bind LDL-cholesterol particles, internalize them and the levels of cholesterol in the blood will fall [12]. Despite statins' unequivocal lipid-lowering efficacy, patients show large interindividual differences in response to statin medication $[13,14]$. Various pharmacogenetics studies and genome-wide association studies (GWAS) have identified genetic polymorphisms as the key influencer of the variability in response observed with statins across patients, principally in genes involved in cholesterol homeostasis [15-17]. These studies have shown that the SNPs (single nucleotide polymorphisms) are related to not only the therapeutic effect of statin but also blood lipid level, consequently the risk of developing cardiovascular disease (CVD) [18-20].

Functional genomics and mutational analysis with the advancement of bioinformatics tools have already provided the key advances in disease diagnosis, prognosis, and therapeutic efficacy [21-35]. However, the in silico analysis of non-coding SNPs and coding SNPs of the HMGCR gene remains unpredictable to date. Among which missense coding SNPs are thought to have the principal impact on phenotype and may exert deleterious effects on the structure, function, solubility, or stability of proteins. Hence, this investigation aims to characterize the deleterious mutations of HMGCR gene. Our study involved the following- (a) retrieval of SNPs in HMGCR gene from available databases, (b) allotting the deleterious missense SNPs to their phenotypic effects, based on sequence and structure-based homology search and detecting the regulatory missense SNPs that can alter the splicing and gene expression patterns, (c) predicting the precise effects of the substitutions of amino acids on secondary structures via solvent accessibility and stability of the structure and (d) and prediction of change in the domain constructions due to the mutations. This study is the first extensive In silico analysis of the HMCGR gene and expected to establish a strong foundation for structurefunction relationship of the enzyme and population specific variation studies in years to come.

\section{Results}


The Flow Chart illustrates the overall procedure of identification and categorization of detrimental SNPs in HMGCR along with the structural and functional consequence analysis upon mutation (Fig. 1).

\section{HMGCR gene is prone to point mutation and rich in missense type}

The HMGCR gene (25783 bp) consists of 23 Exons. Its SNP data for the HMGCR gene were collected from dbSNP as it contains the largest polymorphism database, despite housing both validated and non-validated polymorphism information [22]. The dbSNP contains a total of 6815 SNPs for the gene HMGCR where 388 SNPs were missense SNPs (Fig. 2).

Among 388 submitted missense SNP rsIDs from dbSNP SIFT analyzed 7 missense SNPs to bear a deleterious effect with TI score $\leq 0.05$, results are shown in (Table 1). The corresponding 7 missense SNPs rs112503211, rs113949962, rs147043821, rs147818666, rs148335635, rs193026499, rs368129510 had the tolerance index 0.1 and considered as damaging in HMGCR gene (Table 1).

Table 1

Impact of Amino acid substitution on protein function using the SIFT.

\begin{tabular}{|c|c|c|c|c|c|c|c|c|c|}
\hline SI & SNP & $\begin{array}{l}\text { Ref } \\
\text { allele }\end{array}$ & $\begin{array}{l}\text { Alt } \\
\text { allele }\end{array}$ & $\begin{array}{l}\text { Amino } \\
\text { acid } \\
\text { change }\end{array}$ & Gene ID & Transcript ID & Protein ID & Region & $\begin{array}{l}\text { Sift } \\
\text { prediction }\end{array}$ \\
\hline 1. & rs112503211 & $\mathrm{T}$ & $\mathrm{C}$ & S147P & ENSG00000113161 & ENST00000287936 & ENSP00000287936 & CDS & Deleterious \\
\hline 2. & rs113949962 & G & $A$ & M1I & ENSG00000113161 & ENST00000287936 & ENSP00000287936 & CDS & Deleterious \\
\hline 3. & rs147043821 & $\mathrm{G}$ & $\mathrm{C}$ & L218F & ENSG00000113161 & ENST00000287936 & ENSP00000287936 & CDS & Deleterious \\
\hline 4. & rs147818666 & G & C & G663A & ENSG00000113161 & ENST00000287936 & ENSP00000287936 & CDS & Deleterious \\
\hline 5. & rs148335635 & $A$ & G & N204S & ENSG00000113161 & ENST00000287936 & ENSP00000287936 & CDS & Deleterious \\
\hline 6. & rs193026499 & C & $\mathrm{T}$ & R595C & ENSG00000113161 & ENST00000287936 & ENSP00000287936 & CDS & Deleterious \\
\hline 7. & rs368129510 & C & $\mathrm{T}$ & R159C & ENSG00000113161 & ENST00000287936 & ENSP00000287936 & CDS & Deleterious \\
\hline
\end{tabular}

\section{Coding missense SNPs rs147043821 and rs193026499 are the two most probale damaging mutations in HMGCR}

PolyPhen program was used to determine the missense SNPs with the potential to cause structural modifications due to the amino acid substitution. A total of 388 missense SNP rsIDs were submitted to the PolyPhen server and in the resulting output 27, amino acid substitutions have been reported to be probably damaging with a PSIC score range from 0.539 to 1. Seven missense SNPs (rs112503211, rs113949962, rs147043821, rs147818666, rs148335635, rs193026499 and rs368129510) were identified by SIFT as deleterious, also marked to be damaging by PolyPhen-2 program as well (Table 2). 
Table 2

Functional characterization of missense SNPs by PolyPhen.

\begin{tabular}{|c|c|c|c|c|c|c|c|c|c|}
\hline \multirow[t]{2}{*}{ SI } & \multirow[t]{2}{*}{ SNP } & \multirow{2}{*}{$\begin{array}{l}\text { Protein } \\
\text { Acc }\end{array}$} & \multirow[t]{2}{*}{ Position } & \multirow[t]{2}{*}{ AA1 } & \multirow[t]{2}{*}{ AA2 } & \multicolumn{4}{|c|}{ Prediction/Confidence } \\
\hline & & & & & & Probability & HumDiv & Probability & HumVar \\
\hline \multirow[t]{3}{*}{1.} & \multirow[t]{3}{*}{ rs112503211 } & \multirow[t]{3}{*}{ P04035 } & \multirow[t]{3}{*}{147} & \multirow[t]{3}{*}{$\mathrm{S}$} & \multirow[t]{3}{*}{$\mathrm{P}$} & \multirow{3}{*}{$\begin{array}{l}\text { PROBABLY } \\
\text { DAMAGING }\end{array}$} & Score: 1.000 & \multirow{3}{*}{$\begin{array}{l}\text { PROBABLY } \\
\text { DAMAGING }\end{array}$} & Score: 0.993 \\
\hline & & & & & & & $\begin{array}{l}\text { Sensitivity: } \\
0.00\end{array}$ & & $\begin{array}{l}\text { Sensitivity: } \\
0.47\end{array}$ \\
\hline & & & & & & & $\begin{array}{l}\text { Specificity: } \\
1.00\end{array}$ & & $\begin{array}{l}\text { Specificity: } \\
0.96\end{array}$ \\
\hline \multirow[t]{3}{*}{2.} & \multirow[t]{3}{*}{ rs113949962 } & \multirow[t]{3}{*}{ P04035 } & \multirow[t]{3}{*}{1} & \multirow[t]{3}{*}{ M } & \multirow[t]{3}{*}{ I } & \multirow{3}{*}{$\begin{array}{l}\text { PROBABLY } \\
\text { DAMAGING }\end{array}$} & Score: 0.97 & \multirow{3}{*}{$\begin{array}{l}\text { POSSIBLY } \\
\text { DAMAGING }\end{array}$} & Score: 0.650 \\
\hline & & & & & & & $\begin{array}{l}\text { Sensitivity: } \\
0.77\end{array}$ & & $\begin{array}{l}\text { Sensitivity: } \\
0.79\end{array}$ \\
\hline & & & & & & & $\begin{array}{l}\text { Specificity: } \\
0.95\end{array}$ & & $\begin{array}{l}\text { Specificity: } \\
0.84\end{array}$ \\
\hline \multirow[t]{3}{*}{3.} & \multirow[t]{3}{*}{ rs147043821 } & \multirow[t]{3}{*}{ P04035 } & \multirow[t]{3}{*}{218} & \multirow[t]{3}{*}{ L } & \multirow[t]{3}{*}{$\mathrm{F}$} & \multirow{3}{*}{$\begin{array}{l}\text { PROBABLY } \\
\text { DAMAGING }\end{array}$} & Score: 1.000 & \multirow{3}{*}{$\begin{array}{l}\text { PROBABLY } \\
\text { DAMAGING }\end{array}$} & Score: 1.000 \\
\hline & & & & & & & $\begin{array}{l}\text { Sensitivity: } \\
0.00\end{array}$ & & $\begin{array}{l}\text { Sensitivity: } \\
0.00\end{array}$ \\
\hline & & & & & & & $\begin{array}{l}\text { Specificity: } \\
1.00\end{array}$ & & $\begin{array}{l}\text { Specificity: } \\
1.00\end{array}$ \\
\hline \multirow[t]{3}{*}{4.} & \multirow[t]{3}{*}{ rs147818666 } & P04035 & 663 & G & A & $\begin{array}{l}\text { POSSIBLY } \\
\text { DAMAGING }\end{array}$ & & $\begin{array}{l}\text { POSSIBLY } \\
\text { DAMAGING }\end{array}$ & Score: 0.519 \\
\hline & & & & & & & $\begin{array}{l}\text { Sensitivity: } \\
0.86\end{array}$ & & $\begin{array}{l}\text { Sensitivity: } \\
0.82\end{array}$ \\
\hline & & & & & & & $\begin{array}{l}\text { Specificity: } \\
0.91\end{array}$ & & $\begin{array}{l}\text { Specificity: } \\
0.81\end{array}$ \\
\hline 5. & rs148335635 & P04035 & 204 & $\mathrm{~N}$ & S & $\begin{array}{l}\text { PROBABLY } \\
\text { DAMAGING }\end{array}$ & & $\begin{array}{l}\text { PROBABLY } \\
\text { DAMAGING }\end{array}$ & Score: 0.999 \\
\hline & & & & & & & $\begin{array}{l}\text { Sensitivity: } \\
0.00\end{array}$ & & $\begin{array}{l}\text { Sensitivity: } \\
0.09\end{array}$ \\
\hline & & & & & & & $\begin{array}{l}\text { Specificity: } \\
1.00\end{array}$ & & $\begin{array}{l}\text { Specificity: } \\
0.99\end{array}$ \\
\hline 6. & rs193026499 & P04035 & 595 & $\mathrm{R}$ & C & PROBABLY & Score: 0.999 & $\begin{array}{l}\text { PROBABLY } \\
\text { DAMAGING }\end{array}$ & Score: 0.983 \\
\hline & & & & & & & $\begin{array}{l}\text { Sensitivity: } \\
0.14\end{array}$ & & $\begin{array}{l}\text { Sensitivity: } \\
0.56\end{array}$ \\
\hline & & & & & & & $\begin{array}{l}\text { Specificity: } \\
0.99\end{array}$ & & $\begin{array}{l}\text { Specificity: } \\
0.94\end{array}$ \\
\hline 7. & rs368129510 & P04035 & 159 & $\mathrm{R}$ & $\mathrm{C}$ & PROBABLY & Score: 1.000 & PROBABLY & Score: 0.939 \\
\hline & & & & & & & $\begin{array}{l}\text { Sensitivity: } \\
0.00\end{array}$ & & $\begin{array}{l}\text { Sensitivity: } \\
0.66\end{array}$ \\
\hline & & & & & & & $\begin{array}{l}\text { Specificity: } \\
1.00\end{array}$ & & $\begin{array}{l}\text { Specificity: } \\
0.91\end{array}$ \\
\hline
\end{tabular}

To further validate the results of the tools used beforehand we analyzed the missense SNPs with the following in silico SNP prediction algorithms: PMUT, SNAP, PANTHER, MUTPRED, and SNP \& GO. The missense SNPs which are marked as deleterious by both SIFT and Poly-Phen2 server were principally selected. The results generated from the abovementioned tools were further combined and compared with the result of SIFT and PolyPhen server. In the combined results of 388 missense SNPs, only 7 (rs114166108, rs113949962, rs182539049, rs145415894, rs142939718, rs35896902, and rs150721457) were predicted as disease-related by at least 5 out of the 7 tools (Fig. 3 ).

Two missense SNPs, rs147043821 and rs193026499, showed positive results in all the 7 tools (Table 3-7). 
Table 3

Disease association study of missense SNPs by PMUT.

\begin{tabular}{|lllllll|}
\hline SI & SNP & Protein & Position & Mutation & Prediction & \\
\hline 1. & rs112503211 & P04035 & 147 & $\mathrm{~S} \rightarrow \mathrm{P}(\mathrm{Ser} \rightarrow \mathrm{Pro})$ & $0.48(83 \%)$ & Neutral \\
\hline 2. & $\mathrm{rs} 113949962$ & $\mathrm{P} 04035$ & 1 & $\mathrm{M} \rightarrow \mathrm{I}(\mathrm{Met} \rightarrow \mathrm{lle})$ & $0.60(83 \%)$ & Disease \\
\hline 3. & $\mathrm{rs} 147043821$ & $\mathrm{P} 04035$ & 218 & $\mathrm{~L} \rightarrow \mathrm{F}(\mathrm{Leu} \rightarrow \mathrm{Phe})$ & $0.55(81 \%)$ & Disease \\
\hline 4. & $\mathrm{rs} 147818666$ & $\mathrm{P} 04035$ & 663 & $\mathrm{G} \rightarrow \mathrm{A}(\mathrm{Gly} \rightarrow \mathrm{Ala})$ & $0.43(85 \%)$ & Neutral \\
\hline 5. & $\mathrm{rs} 148335635$ & $\mathrm{P} 04035$ & 204 & $\mathrm{~N} \rightarrow \mathrm{S}($ Asn $\rightarrow \mathrm{Ser})$ & $0.48(83 \%)$ & Neutral \\
\hline 6. & $\mathrm{rs} 193026499$ & $\mathrm{P} 04035$ & 595 & $\mathrm{R} \rightarrow \mathrm{C}($ Arg $\rightarrow \mathrm{Cys})$ & $0.79(89 \%)$ & Disease \\
\hline 7. & $\mathrm{rs} 368129510$ & $\mathrm{P} 04035$ & 159 & $\mathrm{R} \rightarrow \mathrm{C}($ Arg $\rightarrow \mathrm{Cys})$ & $0.48(83 \%)$ & Neutral \\
\hline
\end{tabular}

Table 4

Prediction of damaging effect of SNP in HMGCR gene by SNAP2.

\begin{tabular}{|llllllll|}
\hline SI & SNP & Wildtype Amino Acid & Position & Variant Amino Acid & Predicted Effect & Score & Expected Accuracy \\
\hline 1. & rs112503211 & S & 147 & P & neutral & -22 & $61 \%$ \\
2. & rs113949962 & M & 1 & I & neutral & -27 & $61 \%$ \\
\hline 3. & rs147043821 & L & 218 & F & effect & 12 & $59 \%$ \\
\hline 4. & rs147818666 & G & 663 & A & effect & 5 & $53 \%$ \\
\hline 5. & rs148335635 & N & 204 & S & Effect & 48 & $71 \%$ \\
\hline 6. & rs193026499 & R & 595 & C & effect & 47 & $71 \%$ \\
\hline 7. & rs368129510 & R & 159 & C & effect & 73 & $85 \%$ \\
\hline
\end{tabular}

Table 5

Damagicity prediction of polymorphism by PANTHER.

\begin{tabular}{|lllll|}
\hline SI & SNP & Substitution & Preservation time & Message \\
\hline 1. & rs112503211 & S147P & 673 & probably damaging \\
2. & rs113949962 & M1I & 3807 & probably damaging \\
\hline 3. & rs147043821 & L218F & 673 & probably damaging \\
\hline 4. & rs147818666 & G663A & 3806 & probably damaging \\
\hline 5. & rs148335635 & N204S & 673 & probably damaging \\
\hline 6. & rs193026499 & R595C & 673 & probably damaging \\
\hline 7. & rs368129510 & R159C & 673 & probably damaging \\
\hline
\end{tabular}


Table 6

Effect in functional Motif in HMGCR gene by MUTPRED tool.

\begin{tabular}{|c|c|c|c|c|c|}
\hline SI & SNP & Substitution & $\begin{array}{l}\text { MutPred2 } \\
\text { Score }\end{array}$ & Affected PROSITE and ELM Motifs & Molecular mechanisms with P-values $<=0.05$ \\
\hline 1. & rs112503211 & S147P & 0.652 & $\begin{array}{l}\text { ELME000063, ELME000064, } \\
\text { ELME000136, ELME000159, } \\
\text { ELME000202, ELME000239, } \\
\text { ELME000249, ELME000 }\end{array}$ & $\begin{array}{l}\text { Gain of Phosphorylation at S146, Prob: } 0.29, \mathrm{P}- \\
\text { value: } 0.02 \text {; } \\
\text { Altered Transmembrane protein, Prob: } 0.17, \mathrm{P}- \\
\text { value: } 9.1 \mathrm{e}-03 \text {; } \\
\text { Loss of Ubiquitylation at K142, Prob: } 0.16, \mathrm{P}- \\
\text { value: } 0.03 \text {; } \\
\text { Loss of GPI-anchor amidation at N148, Prob: } 0.03 \text {, } \\
\text { P-value: } 8.4 \mathrm{e}-03\end{array}$ \\
\hline 2. & rs113949962 & M1I & 0.881 & ELME000355 & $\begin{array}{l}\text { Altered Disordered interface, Prob: } 0.39, \text { P-value: } \\
\text { 5.1e-03; } \\
\text { Altered Ordered interface, Prob: } 0.27, \text { P-value: } \\
\text { 5.6e-03; } \\
\text { Altered Signal peptide, Prob: } 0.18, \text { P-value: } 8.8 \mathrm{e}- \\
04 ; \\
\text { Loss of N-terminal acetylation at M1, Prob: } 0.03 \text {, } \\
\text { P-value: } 5.6 \mathrm{e}-03\end{array}$ \\
\hline 3. & rs147043821 & L218F & 0.781 & $\begin{array}{l}\text { ELME000239, ELME000333, } \\
\text { ELME000335 }\end{array}$ & $\begin{array}{l}\text { Loss of Helix, Prob: 0.33, P-value: 1.2e-03; } \\
\text { Gain of Strand, Prob: 0.28, P-value: 7.5e-03 }\end{array}$ \\
\hline 4. & rs147818666 & G663A & 0.856 & ELME000063, PS00008 & $\begin{array}{l}\text { Gain of Helix, Prob: } 0.28 \text {, P-value: } 0.03 \text {; Loss of } \\
\text { Allosteric site at M659, Prob: } 0.24, \text { P-value: } 0.02 \text {; } \\
\text { Loss of Acetylation at K662, Prob: } 0.24 \text {, P-value: } \\
0.02\end{array}$ \\
\hline 5. & rs193026499 & R595C & 0.569 & ELME000155 & $\begin{array}{l}\text { Altered Ordered interface, Prob: 0.31, P-value: } 0.01 \\
\text { Gain of Allosteric site at R590, Prob: } 0.24, \text { P-value: } \\
0.01 \\
\text { Loss of Catalytic site at R590, Prob: } 0.22, \text { P-value: } \\
8.8 \mathrm{e}-03 \\
\text { Gain of ADP-ribosylation at R598, Prob: } 0.19, \text { P- } \\
\text { value: } 0.04 \\
\text { Altered Transmembrane protein, Prob: } 0.13, \text { P- } \\
\text { value: } 0.02 \\
\text { Altered Metal binding, Prob: } 0.05, \text { P-value: } 0.04\end{array}$ \\
\hline 6. & rs368129510 & R159C & 0.304 & - & - \\
\hline
\end{tabular}

Table 7

Disease probability prediction of SNP by SNP\&GO.

\begin{tabular}{|c|c|c|c|c|c|c|}
\hline SI & SNP & Mutation & Prediction & RI & Probability & Method \\
\hline 1. & rs112503211 & S147P & Disease & 4 & 0.710 & PhD-SNP: $F[S]=52 \% F[P]=0 \%$ Nali $=66$ \\
\hline 2. & rs113949962 & M1I & Neutral & 3 & 0.352 & PhD-SNP: $F[M]=100 \% F[l]=0 \%$ Nali $=37$ \\
\hline 3. & rs147043821 & L218F & Disease & 4 & 0.713 & PhD-SNP: $F[L]=91 \% F[F]=0 \%$ Nali $=66$ \\
\hline 4. & rs147818666 & G663A & Neutral & 6 & 0.197 & PhD-SNP: $F[G]=62 \% F[A]=33 \%$ Nali $=377$ \\
\hline 5. & rs148335635 & N204S & Disease & 6 & 0.820 & PhD-SNP: $F[N]=75 \% F[S]=0 \%$ Nali $=66$ \\
\hline 6. & rs193026499 & R595C & Disease & 6 & 0.793 & PhD-SNP: $F[R]=51 \% F[C]=0 \%$ Nali $=356$ \\
\hline 7. & rs368129510 & R159C & Disease & 6 & 0.806 & PhD-SNP: $F[R]=52 \% F[C]=0 \%$ Nali $=66$ \\
\hline
\end{tabular}




\section{High-Risk Missense SNPs are located in the conserved region}

Biological processes rely on functional sites of proteins such as catalytic sites, allosteric sites, and protein-protein interaction sites. Amino acids present in these biologically active sites tend to be highly conserved, compared to any other residues in the protein. Any substitution of these residues generally leads to complete loss of biological functions and render severe damaging effect to the biological process itself [25]. The retrieved amino acid corresponding to missense SNPs was utilized to identify the suitable template to build the 3D structure. To predict the 3D structure retrieved amino acid sequence was submitted to the NCBI protein BLAST tool to recognize the structure of the closest related proteins. The structure PDB ID: 3cd5 with 99.8\% identity was selected and built 3D structure. Later, the InterEvDock2 server was used to calculate the degree of evolutionary conservation at each amino acid position of the HMGCR protein. InterEvDock2 identifies putative structural and functional residues and determine their evolutionary conservation [26]. Although a complete analysis was done, we focused on the conservation profile of the selected 7 high-risk missense SNP locations. The analysis showed that residues S147, M1, L218, G663, N204, R595, and R159 are highly conserved (Fig.4).

These conserved residues in HMGCR might have imperative functional importance and are identified as functional or structural based on their location relative to the protein surface or the protein core.

\section{High-Risk missense SNPs are capable of inducing proteins unfolding.}

The neural network-based routine tool I-Mutant 2.0 was used for examining the potential modifications in protein stability due to mutations. Models with the following mutations S147, M1, L218, G663, N204, R595, and R159 were submitted to the server for DDG stability prediction and RSA calculation. All the mutations decreased protein stability except rs 113949962 , which is shown to be increasing structural stability ( 0.58 $\mathrm{Kcal} / \mathrm{mol})$. Mutation rs368129510 accounted for the lowest DDG value $(-3.34 \mathrm{kcal} / \mathrm{mol})$, meaning to be more unstable due to this mutation (Fig.5).

\section{Figure 5: Free Energy Calculation of polymorphisms.}

All other mutations rs112503211, rs147043821, rs147818666 and rs193026499 have the DDG values respectively - $0.88 \mathrm{kcal} / \mathrm{mol},-1.27$ $\mathrm{kcal} / \mathrm{mol},-0.67 \mathrm{kcal} / \mathrm{mol}$ and $-0.56 \mathrm{kcal} / \mathrm{mol}$; this suggests decreased protein stability, due to DDG values being less than 0 (Fig. 5 ). Further, we have also analyzed the Surface Accessibility Surface Area (SASA) and angles of the protein structure of alpha helix and beta sheet in both wild and mutant models of HMGCR. All the mutations reside in alpha helix and beta sheet which can induce the conformational change in protein (Table 8).

Table 8

Structural Variation upon the Mutational Impact.

\begin{tabular}{|c|c|c|c|c|c|c|c|}
\hline SI & Muation & Mutation Type & Residue Name and Number & Structure & SASA & Phi Angle & Psi Angle \\
\hline \multirow[t]{2}{*}{1.} & \multirow[t]{2}{*}{ rs112503211 } & Wild & S147 & \multirow[t]{2}{*}{ Coil } & 15.4 & -57.58 & 144.73 \\
\hline & & Mutant & 147P & & 18.8 & -60.07 & 140.74 \\
\hline \multirow[t]{2}{*}{2.} & \multirow[t]{2}{*}{ rs368129510 } & Wild & R159 & Alpha Helix & 85.6 & -57.10 & -39.91 \\
\hline & & Mutant & $159 \mathrm{C}$ & Alpha Helix & 68.3 & -66.57 & -41.71 \\
\hline \multirow[t]{2}{*}{3.} & \multirow[t]{2}{*}{ rs147043821 } & Wild & L218 & Alpha Helix & 21.4 & -65.25 & -40.28 \\
\hline & & Mutant & $218 \mathrm{~F}$ & Alpha Helix & 78.2 & -64.22 & -44.63 \\
\hline \multirow[t]{2}{*}{4.} & \multirow[t]{2}{*}{ rs193026499 } & Wild & R595 & Beta Sheet & 2.5 & 125.89 & 145.20 \\
\hline & & Mutant & $595 C$ & Beta Sheet & 67.7 & 126.90 & 144.29 \\
\hline \multirow[t]{2}{*}{5.} & \multirow[t]{2}{*}{ rs147818666 } & Wild & $\mathrm{G} 663$ & Alpha Helix & 0.0 & -64.63 & -39.48 \\
\hline & & Mutant & $663 \mathrm{~A}$ & Alpha Helix & 0.0 & -64.96 & -39.53 \\
\hline
\end{tabular}

SASA may change due to mutation when the amino acid substitution is occurred. Here, the SASA value has been changed in all the mutations except rs147818666. The SASA value of rs368129510 has been slightly decreased than the wild type model. The increasing SASA value of the 
mutations rs147043821 and rs193026499 may lead to the unfolding of the protein 3D structure, meaning to the loss of the biological functions of the HMGCR gene (Table 8).

\section{High risk polymorphisms are likely to alter the Domain Structures of HMGCR}

The Prosite-ExPasy tool was used to search for domain structures in HMGCR and map the mutations in the domains for determining the changes they might cause in the domain structures. The tool searches the UNIProtKB database for motifs and in the produced result showed SterolSensing Domain (SSD) and Hydroxymethylglutaryl-coenzyme A reductase (HMG-Co-A) domain in HMGCR. The SSD domain consists of 61-218 amino acid region in the HMGCR gene and HMG-Co-A is composed of 464-871 amino acid residues in the HMGCR region. All mutations S147, L218, G663, N204, R595, and R159C except 1MI are located in the SSD and HMG-Co-A domain (Fig.6).

\section{Discussion}

Single Nucleotide Polymorphisms (SNPs) are the main cause of most genetic diseases, because more than half of known genetic disorders involve amino acid substitutions. SNPs are exceptional genetic markers and play an important role in disease research because they are dispersed throughout the entire human genome. Although some disease-related SNPs are found in exons or coding regions, there are also SNPs that appear in the intronic regions of genes and interfere with regulatory regions, which in turn affect the splicing process and gene expression. Population based surveys have become tough with the growing number of reported and recorded SNPs, utilizing the sheer number of SNPs data makes it demanding to choose a target for scrutiny which are most likely to contribute to disease development. The dry lab method is a convenient way, in these circumstances to distinguish the deleterious SNPs using dedicated algorithms that can discriminate between neutral and deleterious SNPs by examining the databases and combining functional and structural evidence about the ultimate effect of a polymorphism.

Search for missense SNPs in dbSNP against HMGCR resulted in 6815 hits. The rsIDs of which were queried into SIFT and PolyPhen-2 servers. From the total SNPs of HMGCR, we selected only missense polymorphism for further investigation as it can have an effect on protein structure. We analyzed 388 missense polymorphisms by employing seven tools to observe how deleterious effect they can exert upon the protein structure (Fig. 2). 7 SNPs were predicted deleterious in common in both SIFT and Recent studies have found several accounts indicating HMGCR linkage to cholesterol biosynthesis but there remains a significant amount of polymorphism data on HMGCR that awaits extensive population based and clinical studies. In this current study, the SNP databases were analyzed to find out SNPs that might potentially be deleterious for HMGCR through the employment of computational methods. Polyphen-2 algorithms. Furthermore, we analyzed the data with several other SNP analyzing algorithms and in a combined result also 7 missense SNPs were predicted deleterious. We have employed SIFT, PolyPhen, PMUT, SNAP, PANTHER, MUTPRED, and SNP \& GO algorithms to characterize the 388 missense SNPs found available in the database. However, only seven polymorphisms rs112503211, rs113949962, rs147043821, rs147818666, rs148335635, rs193026499 and rs368129510 have shown the deleterious effect upon the protein structure (Fig. 3, Table 1-7). We have employed the InterEvDock2 server to find out the conserveness of the wild residues. We have found these residues are in the conserved region and if these residues alter the protein structure would be hampered to initiate its normal activity (Fig. 4). The predicted SNPs are located in the SSD and HMG-CoA domains of the protein, which ultimately, may hamper the biological activity of HMGCR. Mutations in SSD could be a barrier to sense the sterol for cholesterol regulation into our body (Fig. 6). For further analysis, we have explored the protein data bank that contained a structure (3cd5) with 99.8\% identity with HMGCR. We performed a free energy calculation of the mutant and wild type models. The free energy of all the mutated models declined considerably from the wild type models. We have found all the selected polymorphisms S147, M1, L218, G663, N204, R595, and R159 have shown the protein de-stability upon the polymorphism except M1 (Fig. 5). Further, we have utilized the stride server by which we have observed the structural variation of the mutant models. A mutation may alter the folding pattern of the protein due to change an amino acid with another. Therefore, protein function can be lost and ultimately prompting the disease condition. The selected polymorphism rs112503211 (S147P), rs147043821 (L218F), rs193026499 (R595C), and rs368129510 (R159C) changed the Solvent Accessible Surface Area (SASA), Phi and Psi angle than the wild type models. The polymorphism rs147818666 (G663A) did not show any changes in the mutant model. It is to be noted that rs368129510 (R159C) and rs147043821 (L218F) changed in the alpha helix motif whereas rs193026499 (R595C) showed the changes in the beta sheet motif. Therefore, these three polymorphisms rs368129510 (R159C), rs147043821 (L218F), and rs193026499 (R595C) might change the folding pattern and stability of the protein.

In process of this study, it was observed that despite some correct assumption the web-based tools need to be more precise in detecting deleterious SNPs and population-based studies are essential to recognize and examine the predicted SNPs in different populations. By crossreferencing all the data from the seven algorithms, we observed two SNPs rs147043821 and rs193026499 have shown the damaging effect in all seven algorithms; therefore, these two could be the most promising polymorphism in the HMGCR.

HMGCR is embedded in the endoplasmic reticulum (ER) membrane. It consists of two distinct domains: N-terminal domain or Sterol Sensing Domain (SSD) and C-terminal domain or Catalytic Domain. SSD anchors the protein in ER membrane that senses sterol or cholesterol level in the 
cell. It either directly or indirectly can sense the intracellular level of sterol/cholesterol. The catalytic domain is protruded in the cytosol and contains all the catalytic activities of HMGCR. The SSD of HMGCR senses the excess level of sterol/cholesterol in the cell and the sensing result might induces a conformational change in SSD. This causes the protein susceptible to rapid Sterol induced degradation. Whenever there is enough cholesterol present in the cell, HMGCR undergoes proteolysis, and thereby the quantity of HMGCR is decreased. When SNPs are present in SSD, it may fail to sense intracellular cholesterol levels as a result proteolysis of HMGCR does not occur. When present in the catalytic domain, SSD can sense cholesterol level but the further steps of Enodplasmic Reticulum Associated Degradation (ERAD) may be hampered and hence, catalytic domains fail to be degraded. So, rs147043821 in SSD or rs193026499 in the catalytic domain of HMGCR would hamper feedback regulation and upsurge the hypercholesterolemia, which might be a great concern for the health (Fig. 7).

Therefore, these SNPs rs147043821 and rs193026499 should be evaluated in wet lab experiment.

\section{Conclusion}

The present study analyzed the SNPs of HMGCR gene and predicted seven deleterious SNPs including rs112503211, rs113949962, rs147043821, rs147818666, rs148335635, rs193026499 and rs368129510 through SNP analyzing tools. Among them, rs147043821 and rs193026499 are most likely to have the detrimental effect in the HMGCR gene. The results of this study will hopefully help to distinguish the damaging SNPs which increase the risk of cholesterol Biosynthesis in patients from different populations in future genome-wide studies. Therefore, widespread population-based studies and clinical studies are prerequisites to characterize the immense SNP data and for the substantiation of the outcomes of the present study.

\section{Methods}

\section{Retrieval of SNP Datasets}

SNP of HMGCR gene and their protein sequences (FASTA format) were retrieved from dbSNP database (http://www.ncbi.nlm.nih.gov/SNP/) for computational analysis. Various filters were used for the selection of SNPs related to HMGCR, such as missense, inframe deletion, inframe insertion, initiatior codon variant, and synonymous.

\section{Analysis of Functional Consequences of missense SNPs}

Sorting Intolerant from Tolerant (SIFT) [36] is an algorithm that predicts the potential impact of amino acid substitutions on protein function. This program assumes that evolutionarily conserved regions tend to be less tolerant of mutations, and hence amino acid substitutions or insertions/deletions in these regions are more likely to affect function [36]. It works by searching a query protein against a protein database to obtain homologous protein sequences; after apposite sequences are chosen and aligned for a particular position, SIFT aspects the composition of amino acids and calculates the score. All the retrieved mutations (rs ID) were submitted to this tool. A SIFT score ranges from 0 to 1 , it is a standardized probability of perceiving the new amino acid at that position. It also calculates the tolerance index ( $\mathrm{TI}$ ) of a particular amino acid substitution. SIFT score is classified as tolerant (ranging from 0.201 to 1.00$)$ or intolerant $(0.051-0.10)$ and borderline (0.101-0.20). Hence, an SNP's functional consequence is inversely proportional to the tolerance index (TI) [37]. In this study, the identification numbers (rsIDs) of each SNP of human HMGCR gene obtained from NCBI were submitted as a query sequence to SIFT for homology searching. The SIFT score of $\leq 0.05$ indicates the deleterious effect of missense variants on protein function.

\section{Functional Consequences of missense SNPs by Structural Homology}

To comprehend the functional significance of a protein it is essential to scrutinize the damaged coding missense SNPs at the structural level. Polymorphism Phenotyping-2 or PolyPhen-2 [38] is an automatic tool for the prediction of the possible impact of an amino acid substitution on the structure and function of a human protein. To understand the functional consequence, the protein sequence of our gene along with mutational position and two amino acid variants was submitted as the query. The PolyPhen-2 calculates the posterior probability that a missense SNP is damaging by a Bayesian classifier [39]. The conservation of a position in the MSA and the deleterious effect on the protein structure results in the Position-Specific Independent Count (PSIC) score that ranges from 0 to 1 [38]. The categorization of the missense SNPs results in Possibly Damaging and Probably Damaging (PSIC > 0.5) or Benign (PSIC < 0.5). PolyPhen-2 also calculates the score difference between variants, the higher the PSIC score difference is, the higher the functional impact a specific amino acid substitution is likely to have.

\section{Characterization of Functional missense SNPs}


SNPs \& GO $[40,41]$ was used for the characterization of functional missense SNPs. The impact of protein variations was predicted via the SNPs \& GO algorithms, using functional information categorized by Gene Ontology (GO) terms of the three main roots: Molecular Function, Biological Process, and Cellular Component. The selected SNPs were submitted into this tool to determine the functional insights. The sequence profile is then calculated by performing one run of BLAST against the UniRef90 dataset to select homologous sequences with an E-value lower than 10-9. The algorithm uses a support vector machine (SVM) based analyzing method, which includes the sequence environment of the variation and a log-odd score calculated considering all the Gene Ontology terms connected to the mutated protein and their parents in the GO graph. A probability score higher than 0.5 reveals the disease-related effect of mutation on the protein function [41].

PANTHER cSNP (Protein ANalysis THrough Evolutionary Relationship_coding_SNP) (http://pantherdb.org/tools/csnpScoreForm.jsp) calculates the likelihood of a single AA change on protein function, and it is based on the PANTHER-PSEP (Position_Specific Evolutionary Preservation) method [42]. PMUT is based on the use of different kinds of sequence information to label mutations and neural networks to process this information. FASTA sequence was inputted and result was based on the differences among disease related and neutral variations of protein sequence. Probability score higher than 0.5 reveals the disease related effect of mutation on the protein function [43]. MutPred2 is a machine learning-based method and software package that integrates genetic and molecular data to reason probabilistically about the pathogenicity of amino acid substitutions [44]. MutPred2 was utilized to predict the pathogenicity of all the nsSNPs of HMGCR gene. Lastly, SNAP-2 predicts the effects of single amino acid substitutions (SNPs), using neural networks. Visualizes prediction scores as a heatmap [44].

\section{Prediction of Modification in Stability upon Mutation}

To predict the change in stability owed to mutations, the I- Mutant 2.0 server was used. This is a support vector machine (SVM) based tool server, which analyzes the structure or the sequence of the protein. I-Mutant 2.0 is a classifier that can automatically predict the change in protein structural stability upon mutations and it also acts as a regression estimator which predicts the change in Gibbs free energy differences between the mutated and wild type protein in $\mathrm{kcal} / \mathrm{mol}[45]$.

\section{Missense SNP in Functional region}

Pfam server was used to discern the location of missense SNP into the functional region in protein structure. This is a database of protein families, their annotations, and multiple sequence alignments, which provides a complete and accurate classification of protein families and domains [46]. The identification of domains that occur within proteins can provide insights into their function, thus Pfam was to analyze the functional region of the HMGCR.

\section{Modeling of the Mutated Protein}

The EMBL-EBI Web-based tool Swiss Model workspace was used to find proteins related to the HMGCR gene [47]. The FASTA sequence of HMGCR was given as the query and closest matches were selected from the results. Then a Virtual Mutation (VM) procedure was applied to generate a mutated 3D model of the molecule by substituting amino acids in the atomic models [48]. Accelrys Discovery Studio 4.0 was then used to generate a mutated sequence for the corresponding amino acid substitutions [49]. The regenerated mutant sequences were used further for mutant modeling, which was performed through HHpred Modeller [50], the most popular online protein fold identification server. HHpred chooses the best suitable template and generates a protein model through successive steps, such as profile construction, similarity analysis, and structural properties. A rigorous manner of protein modeling was nominated to get a perfect model.

\section{Location and structural conformation of Mutations}

We have utilized the Stride server (http://webclu.bio.wzw.tum.de/cgi-bin/stride/stridecgi.py) to predict the mutational site upon the 3D structure. This server offers an interactive interface to the secondary structure assignment program STRIDE [51].

\section{Abbreviations}

HMGCR: 3-Hydroxy-3-methylglutaryl-CoA reductase

SNPs: Single Nucleotide Polymorphisms

LDL: low-density lipoprotein

GWAS: genome-wide association studies 
CVD: cardiovascular disease

SASA: Surface Accessibility Surface Area

SSD: Sterol Sensing Domain

Declarations

\section{Availability of data and materials}

The datasets analysed during the current study are available from the corresponding author on reasonable request.

\section{Competing interests}

The authors declare that they do not have competing interests on this work.

\section{Funding sources}

The author(s) received no funding for this work.

\section{Authors Contribution}

MS \& SA: Conceived, designed, and guided the study, analyzed the data, helped in drafting and performed critical revision. MUH and MM: Analyzed the data and helped in drafting the manuscript. KCD: Helped to design the study, performed bioinformatics analysis, drafted and developed the manuscript and performed critical revision. All authors have approved the manuscript.

\section{Acknowledgments}

We are grateful to the Ministry of Science and Technology for its extensive support

\section{References}

1. Carmena R. Atherogenic Lipoprotein Particles in Atherosclerosis. Circulation. 2004 Jun 15;109(23_suppl_1):III-2III-7.

2. Heller DA, de Faire U, Pedersen NL, Dahlen G, McClearn GE. Genetic and Environmental Influences on Serum Lipid Levels in Twins. New England Journal of Medicine. 1993 Apr 22;328(16):1150-6.

3. Kumar Nigam P. Calculated Low Density Lipoprotein-Cholesterol: Friedewald's Formula versus Other Modified Formulas. International Journal of Life Science and Medical Research. 2014 Apr 25;25-31.

4. Crismaru I, Pantea Stoian A, Bratu OG, Gaman M-A, Stanescu AMA, Bacalbasa N, et al. Low-density lipoprotein cholesterol lowering treatment: the current approach. Lipids in Health and Disease. 2020 May 6;19(1).

5. Park H, Denbow CJ, Cramer CL. Structure and nucleotide sequence of tomato HMG2 encoding 3-hydroxy-3-methyl-glutaryl coenzyme A reductase. Plant Molecular Biology. 1992 Oct;20(2):327-31.

6. Chin DJ, Gil G, Russell DW, Liscum L, Luskey KL, Basu SK, et al. Nucleotide sequence of 3-hydroxy-3-methyl-glutaryl coenzyme A reductase, a glycoprotein of endoplasmic reticulum. Nature. 1984 Apr;308(5960):613-7.

7. Ma S, Sun W, Gao L, Liu S. Therapeutic targets of hypercholesterolemia: HMGCR and LDLR. Diabetes, Metabolic Syndrome and Obesity: Targets and Therapy. 2019 Aug;Volume 12:1543-53.

8. Chen L, Ma M-Y, Sun M, Jiang L-Y, Zhao X-T, Fang X-X, et al. Endogenous sterol intermediates of the mevalonate pathway regulate HMGCR degradation and SREBP-2 processing. Journal of Lipid Research. 2019 Oct;60(10):1765-75.

9. Menzies SA, Volkmar N, van den Boomen DJ, Timms RT, Dickson AS, Nathan JA, et al. The sterol-responsive RNF145 E3 ubiquitin ligase mediates the degradation of HMG-CoA reductase together with gp78 and Hrd1. eLife. 2018 Dec 13;7.

10. Clendening JW, Pandyra A, Boutros PC, Ghamrasni SE, Khosravi F, Trentin GA, et al. Dysregulation of the mevalonate pathway promotes transformation. Proceedings of the National Academy of Sciences. 2010 Aug 9;107(34):15051-6.

11. Loregger A, Raaben M, Tan J, Scheij S, Moeton M, van den Berg M, et al. Haploid Mammalian Genetic Screen Identifies UBXD8 as a Key Determinant of HMGCR Degradation and Cholesterol Biosynthesis. Arteriosclerosis, Thrombosis, and Vascular Biology. 2017

Nov;37(11):2064-74.

Page $11 / 18$ 
12. Endo A. The discovery and development of HMG-CoA reductase inhibitors. Journal of Lipid Research. 1992 Nov;33(11):1569-82.

13. Reiner Ž. Statins in the primary prevention of cardiovascular disease. Nature Reviews Cardiology. 2013 Jun 4;10(8):453-64.

14. Simon JA, Lin F, Hulley SB, Blanche PJ, Waters D, Shiboski S, et al. Phenotypic Predictors of Response to Simvastatin Therapy Among African-Americans and Caucasians: The Cholesterol and Pharmacogenetics (CAP) Study. The American Journal of Cardiology. 2006 Mar;97(6):843-50.

15. Reiner Ž. Resistance and intolerance to statins. Nutrition, Metabolism and Cardiovascular Diseases. 2014 Oct;24(10):1057-66.

16. Schmitz G, Drobnik W. Pharmacogenomics and Pharmacogenetics of Cholesterol-Lowering Therapy. Clinical Chemistry and Laboratory Medicine. 2003 Jan 25;41(4).

17. Barber MJ, Mangravite LM, Hyde CL, Chasman DI, Smith JD, McCarty CA, et al. Genome-Wide Association of Lipid-Lowering Response to Statins in Combined Study Populations. Zanger U, editor. PLoS ONE. 2010 Mar 22;5(3):e9763.

18. Matarín M, Brown WM, Scholz S, Simón-Sánchez J, Fung H-C, Hernandez D, et al. A genome-wide genotyping study in patients with ischaemic stroke: initial analysis and data release. The Lancet Neurology [Internet]. 2007 May 1 [cited 2020 Jun 6];6(5):414-20. Available from: https://www.sciencedirect.com/science/article/abs/pii/S1474442207700819

19. Daley G. The Heart SNPs a Beat Polymorphisms in Candidate Genes for Cardiovascular Disease. Trends in Cardiovascular Medicine. 2001 Feb;11(2):60-6.

20. Liu WY. Probing the Single Nucleotide Polymorphism (Snp) of Swine PPAR Delta Gene. Biotechnology(Faisalabad). 2013 Apr 1;12(4):183-8.

21. Steinmetz LM, Davis RW. Maximizing the potential of functional genomics. Nature Reviews Genetics. 2004 Mar;5(3):190-201.

22. Savonarola A, Palmirotta R, Guadagni F, Silvestris F. Pharmacogenetics and pharmacogenomics: role of mutational analysis in anti-cancer targeted therapy. The Pharmacogenomics Journal. 2012 Jul 3;12(4):277-86.

23. Liang H, Cheung LWT, Li J, Ju Z, Yu S, Stemke-Hale K, et al. Whole-exome sequencing combined with functional genomics reveals novel candidate driver cancer genes in endometrial cancer. Genome Research. 2012 Oct 1;22(11):2120-9.

24. Hossain MU, Khan MdA, Rakib-Uz-Zaman SM, Ali MT, Islam MdS, Keya CA, et al. Treating Diabetes Mellitus: Pharmacophore Based Designing of Potential Drugs fromGymnema sylvestreagainst Insulin Receptor Protein. BioMed Research International. 2016;2016:1-14.

25. Moniruzzaman M, Hossain MU, Islam MN, Rahman MH, Ahmed I, Rahman TA, et al. Coding-Complete Genome Sequence of SARS-CoV-2 Isolate from Bangladesh by Sanger Sequencing. Dennehy JJ, editor. Microbiology Resource Announcements. 2020 Jul 9;9(28).

26. Hossain MU, Omar TMd, Oany AR, Kibria KMK, Shibly AZ, Moniruzzaman Md, et al. Design of peptide-based epitope vaccine and further binding site scrutiny led to groundswell in drug discovery against Lassa virus. 3 Biotech. 2018 Jan 16;8(2).

27. Bhattacharjee A, Hossain MU, Chowdhury ZM, Rahman SMA, Bhuyan ZA, Salimullah M, et al. Insight of druggable cannabinoids against estrogen receptor $\beta$ in breast cancer. Journal of Biomolecular Structure \& Dynamics [Internet]. 2020 Mar 11 [cited 2021 Mar 7];1-10. Available from: https://pubmed.ncbi.nlm.nih.gov/32116130/

28. Hossain MU, Bhattacharjee A, Emon MdTH, Chowdhury ZM, Ahammad I, Mosaib MdG, et al. Novel mutations in NSP-1 and PLPro of SARSCoV-2 NIB-1 genome mount for effective therapeutics. Journal of Genetic Engineering and Biotechnology. 2021 Apr 2;19(1).

29. Hossain MU, Keya CA, Das KC, Hashem A, Omar TMd, Khan MdA, et al. An Immunopharmacoinformatics Approach in Development of Vaccine and Drug Candidates for West Nile Virus. Frontiers in Chemistry. 2018 Jul 6;6.

30. Hossain MU, Khan MdA, Hashem A, Islam MdM, Morshed MN, Keya CA, et al. Finding Potential Therapeutic Targets against Shigella flexneri through Proteome Exploration. Frontiers in Microbiology. 2016 Nov 22;7.

31. Recognition of plausible therapeutic agents to combat COVID-19: An omics data based combined approach. Gene [Internet]. $2021 \mathrm{Mar} 1$ [cited 2021 Apr 9];771:145368. Available from: https://www.sciencedirect.com/science/article/pii/S0378111920310374?via\%3Dihub

32. Moniruzzaman Md, Ahmed I, Huq S, All Mahmud MdS, Begum S, Mahzabin Amin US, et al. Association of polymorphism in heat shock protein 70 genes with type 2 diabetes in Bangladeshi population. Molecular Genetics \& Genomic Medicine. 2019 Dec 9;8(2).

33. Hossain MU, Oany AR, Ahmad SAl, Hasan MdA, Khan MdA, Siddikey MAA. Identification of potential inhibitor and enzyme-inhibitor complex on trypanothione reductase to control Chagas disease. Computational Biology and Chemistry. 2016 Dec;65:29-36.

34. Susmi TF, Rahman A, Khan MdMR, Yasmin F, Islam MdS, Nasif O, et al. Prognostic and clinicopathological insights of phosphodiesterase 9A gene as novel biomarker in human colorectal cancer. BMC Cancer. 2021 May 20;21(1).

35. Hossain MU, Hashem A, Keya CA, Salimullah Md. Therapeutics Insight with Inclusive Immunopharmacology Explication of Human Rotavirus A for the Treatment of Diarrhea. Frontiers in Pharmacology. 2016 Jun 23;7.

36. Sim N-L, Kumar P, Hu J, Henikoff S, Schneider G, Ng PC. SIFT web server: predicting effects of amino acid substitutions on proteins. Nucleic Acids Research [Internet]. 2012 Jun 9 [cited 2019 Apr 17];40(W1):W452-7. Available from:

https://academic.oup.com/nar/article/40/W1/W452/1751364

37. Ng PC. Accounting for Human Polymorphisms Predicted to Affect Protein Function. Genome Research. 2002 Mar 1;12(3):436-46. 
38. Adzhubei I, Jordan DM, Sunyaev SR. Predicting Functional Effect of Human Missense Mutations Using PolyPhen-2. Current Protocols in Human Genetics. 2013 Jan;76(1):7.20.1-41.

39. Adzhubei IA, Schmidt S, Peshkin L, Ramensky VE, Gerasimova A, Bork P, et al. A method and server for predicting damaging missense mutations. Nature Methods. 2010 Apr;7(4):248-9.

40. Capriotti E, Altman RB. Improving the prediction of disease-related variants using protein three-dimensional structure. BMC Bioinformatics. 2011 Jul 5;12(S4).

41. Capriotti E, Calabrese R, Fariselli P, Martelli P, Altman RB, Casadio R. WS-SNPs\&GO: a web server for predicting the deleterious effect of human protein variants using functional annotation. BMC Genomics. 2013;14(Suppl 3):S6.

42. Tang $\mathrm{H}$, Thomas PD. PANTHER-PSEP: predicting disease-causing genetic variants using position-specific evolutionary preservation. Bioinformatics. 2016 May 18;32(14):2230-2.

43. Ferrer-Costa C, Gelpi JL, Zamakola L, Parraga I, de la Cruz X, Orozco M. PMUT: a web-based tool for the annotation of pathological mutations on proteins. Bioinformatics. 2005 May 6;21(14):3176-8.

44. Pejaver V, Urresti J, Lugo-Martinez J, Pagel KA, Lin GN, Nam H-J, et al. Inferring the molecular and phenotypic impact of amino acid variants with MutPred2. Nature Communications. 2020 Nov 20;11(1).

45. Capriotti E, Fariselli P, Casadio R. I-Mutant2.0: predicting stability changes upon mutation from the protein sequence or structure. Nucleic Acids Research. 2005 Jul 1;33(Web Server):W306-10.

46. Sonnhammer E. Pfam: multiple sequence alignments and HMM-profiles of protein domains. Nucleic Acids Research. 1998 Jan 1;26(1):3202.

47. Bordoli L, Kiefer F, Arnold K, Benkert P, Battey J, Schwede T. Protein structure homology modeling using SWISS-MODEL workspace. Nature Protocols. 2008 Dec 11;4(1):1-13.

48. Schieferdecker I, Memon A, Washizaki H. Editorial for the special issue of STVR on the 10th IEEE International Conference on Software Testing, Verification, and Validation (ICST 2017). Software Testing, Verification and Reliability. 2020 Nov 2;

49. Pawar SS, Rohane SH. Review on Discovery Studio: An important Tool for Molecular Docking. Asian Journal Of Research in Chemistry. 2021;14(1):1-3.

50. Soding J, Biegert A, Lupas AN. The HHpred interactive server for protein homology detection and structure prediction. Nucleic Acids Research. 2005 Jul 1;33(Web Server):W244-8.

51. Heinig M, Frishman D. STRIDE: a web server for secondary structure assignment from known atomic coordinates of proteins. Nucleic Acids Research. 2004 Jul 1;32(Web Server):W500-2.

\section{Figures}




\section{Exploration of NCBI dbSNP for HMGCR: 6551 SNPS}

\section{Missense: 388 SNPs}

\section{Deleterious: 7 SNPs}

\section{Figure 1}

Flow diagram of the overall work.

SNP statistis from NCBI data of HMGCR gene

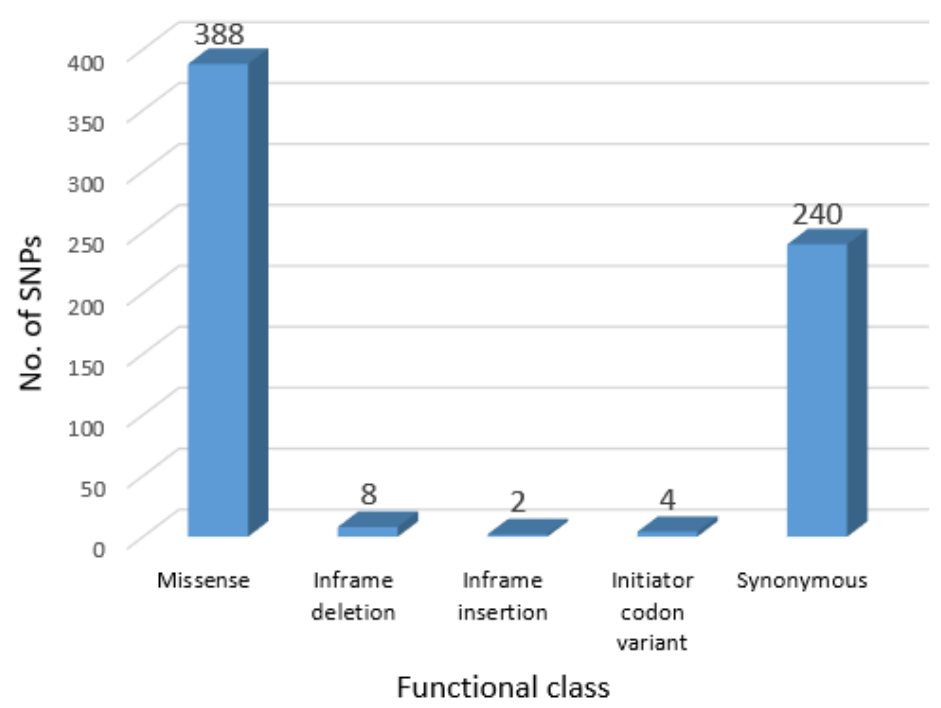

Figure 2

Major functional classes of HMGCR gene polymorphisms. 


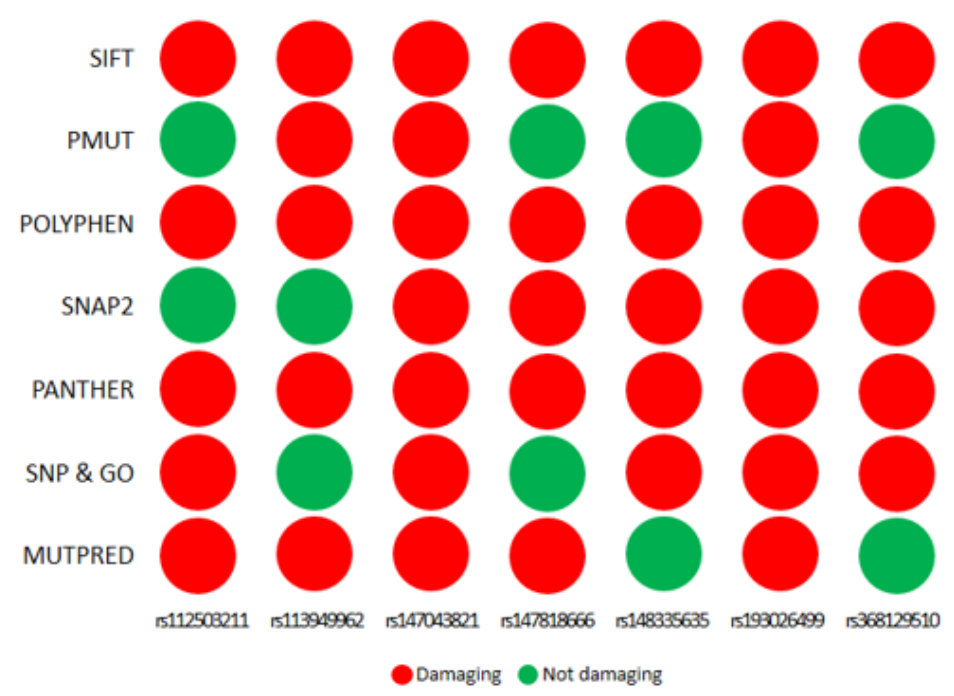

Figure 3

Damagicity of the functional missense SNPs polymorphism.

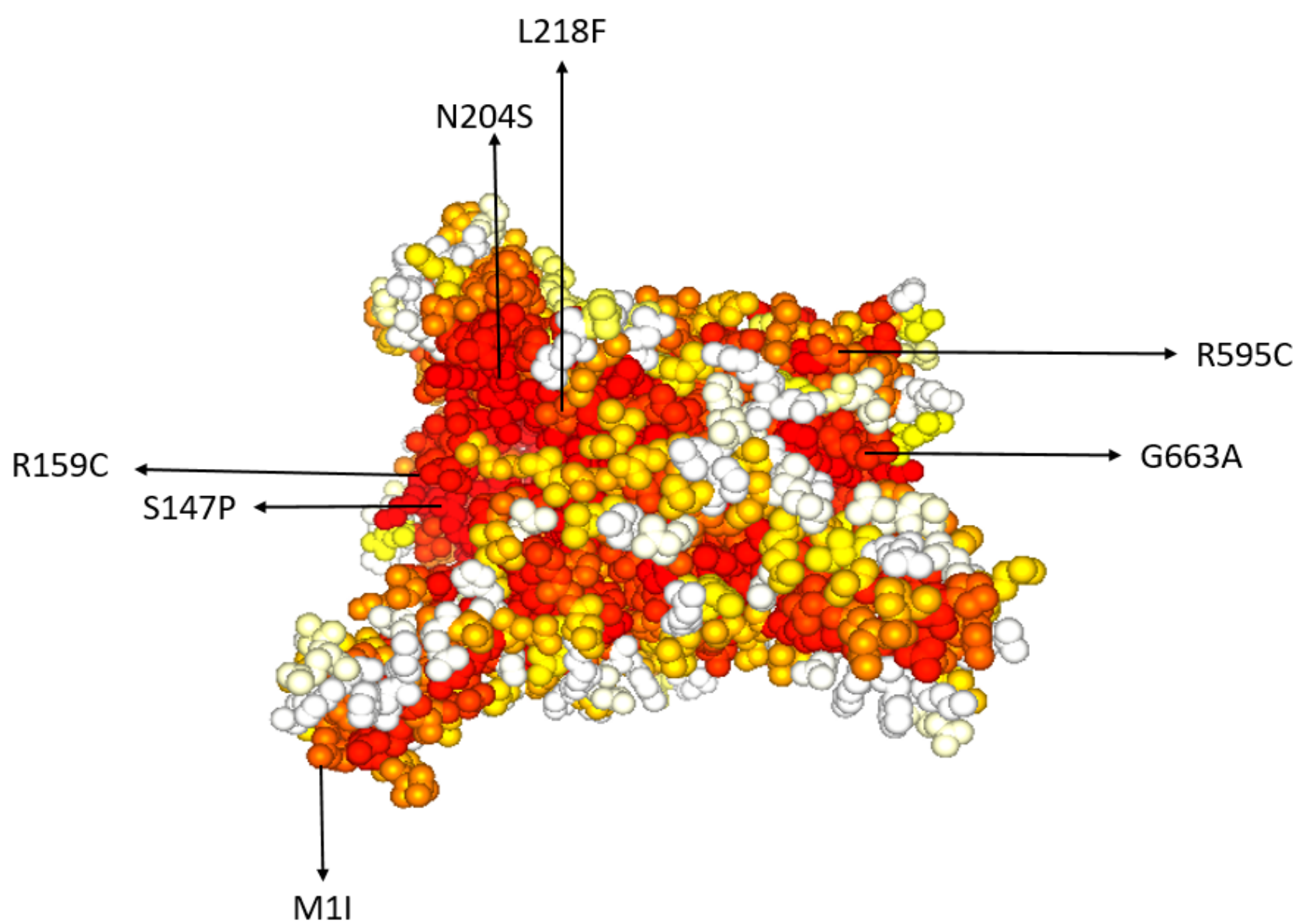

Figure 4

Conservation Profile of functional missense SNPs. Map the conservation index as calculated by the Rate4Site algorithm. Color code is a gradient from red (more conserved) to white (more diverse) through yellow (mild conservation). 


\section{Stability of Polymorphism}

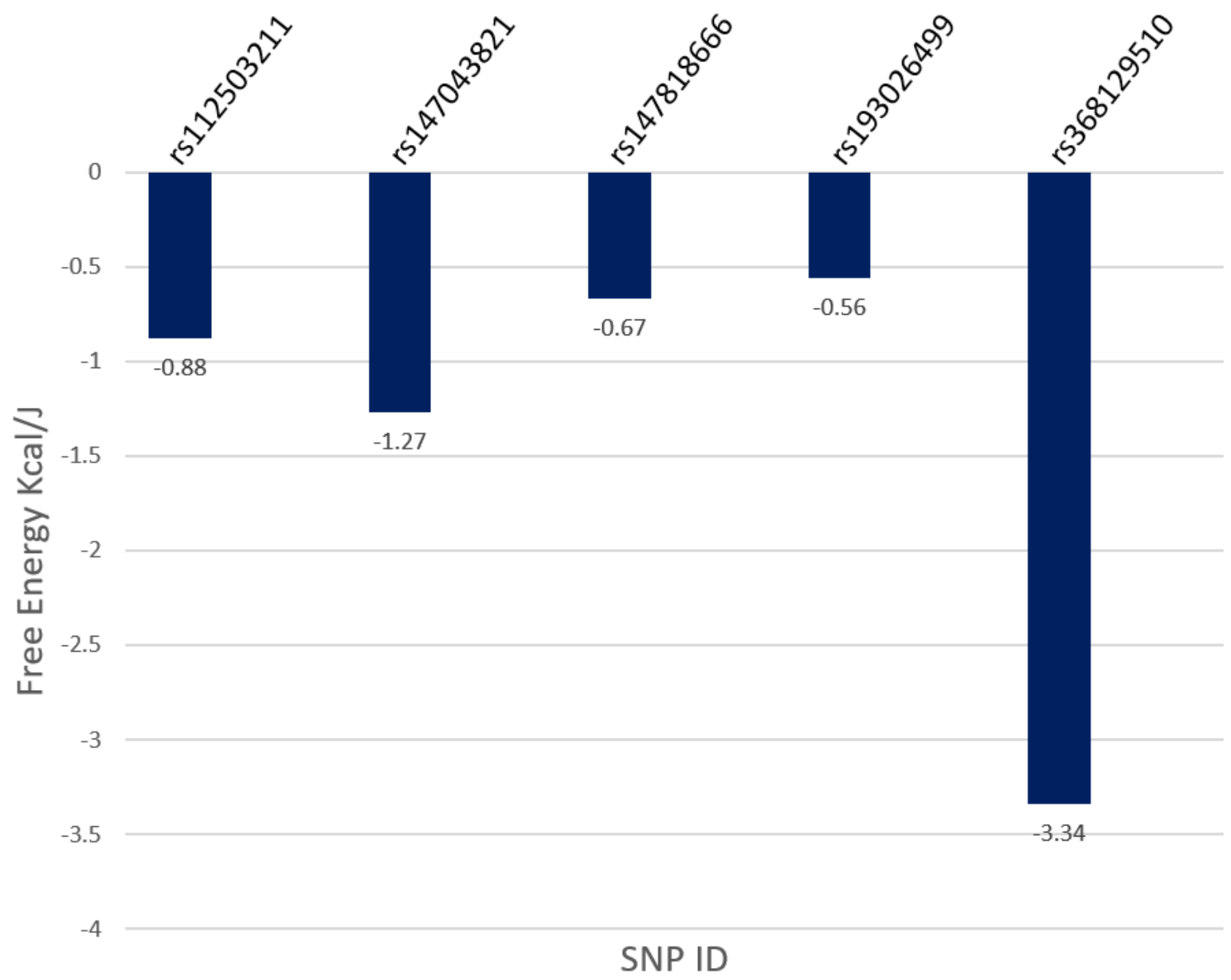

Figure 5

Free Energy Calculation of polymorphisms. 


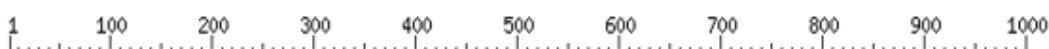

1. rs112503211

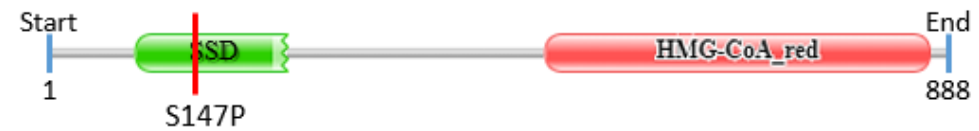

2. rs113949962

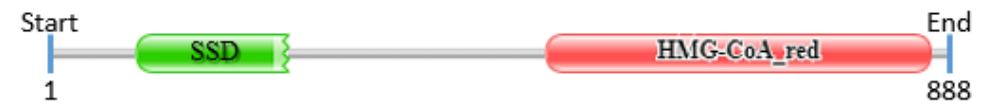

3. rs147043821

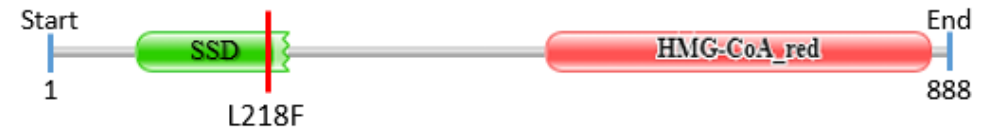

4. rs147818666

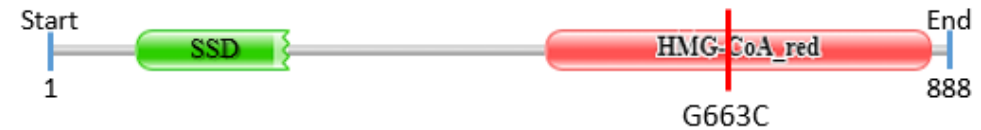

5. rs148335635

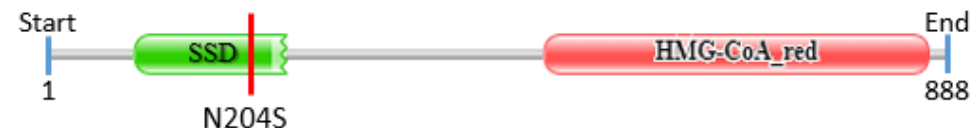

6. rs193026499 $\left.\right|_{1} ^{\text {Start }}$ SSD End

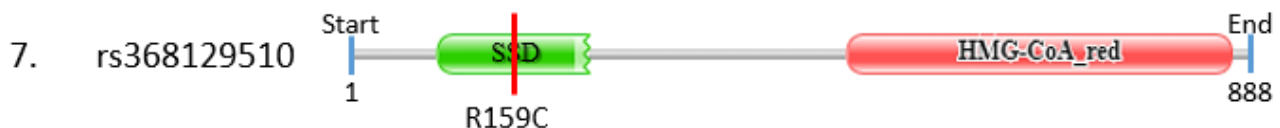

Figure 6

Domain Association of High Risk Polymorphism. 

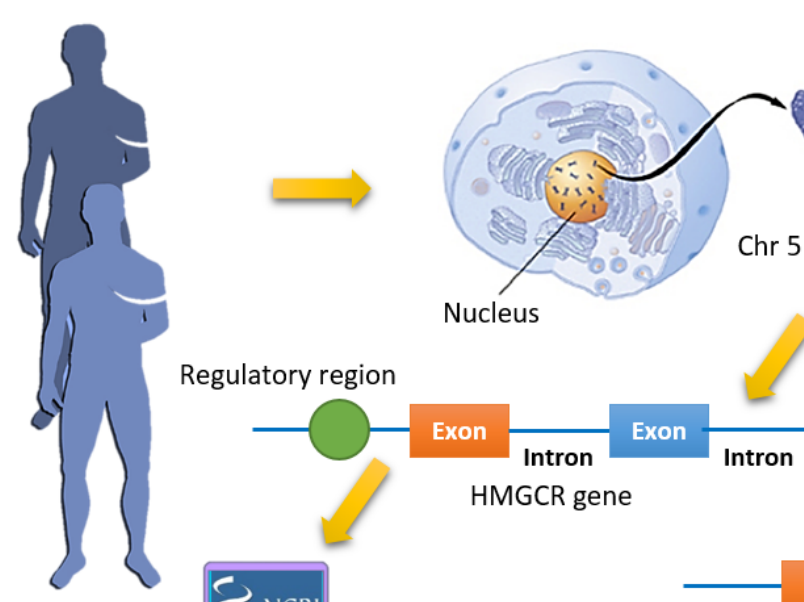

Nucleus

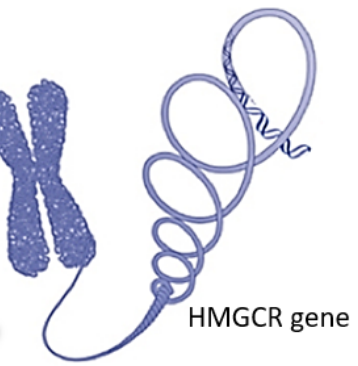

Regulatory region
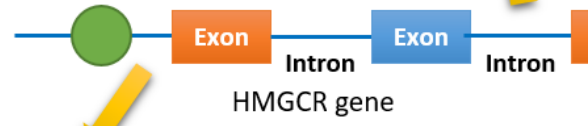

Exon

HMGCR gene

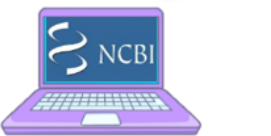

Exploration of NCBI dbSNP

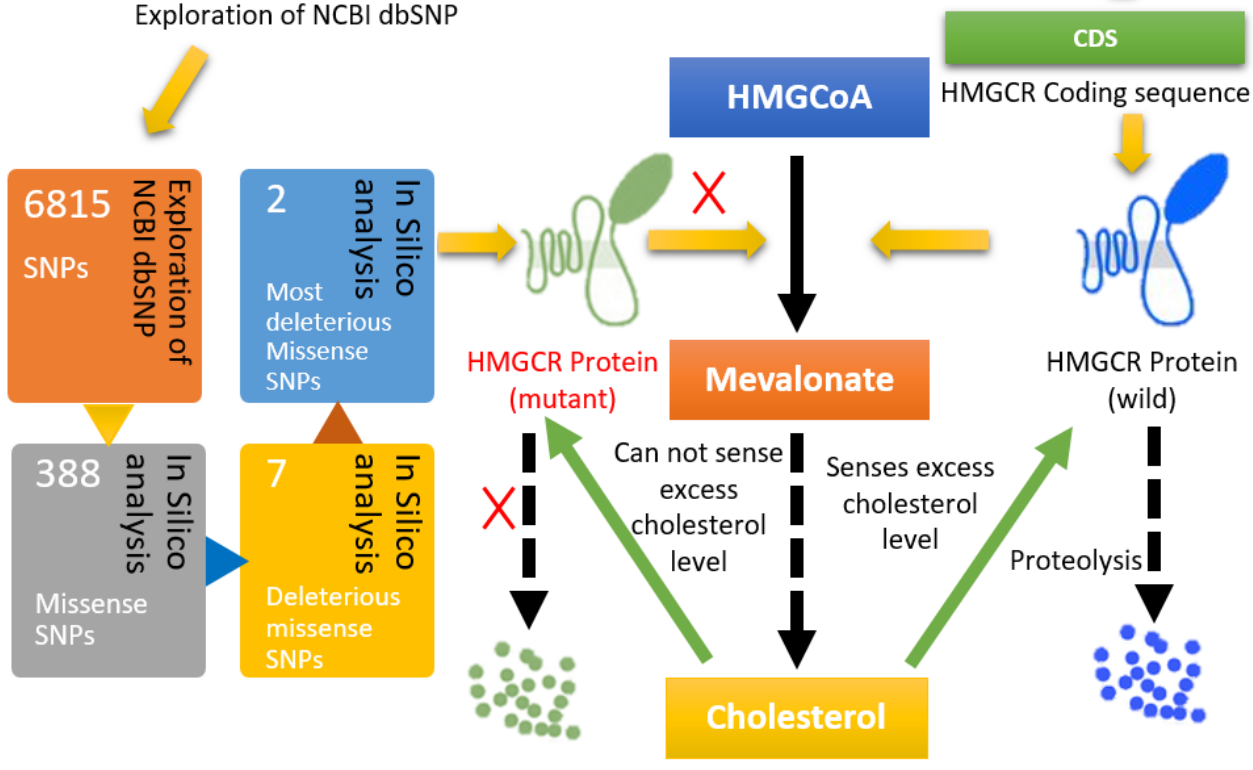

Figure 7

Hypercholesterolemia process by polymorphisms. 